\title{
A Design Modification Approach to Utilize the Benefits of Metal Additive Manufacturing Adoption
}

\author{
Jun Hao Tan, Wee Koon Woon, Wai Leong Eugene Wong \\ School of Mechanical and Systems Engineering, Newcastle University International Singapore (NUIS), Singapore \\ Email: j.h.tan@newcastle.ac.uk, eugene.wong@newcastle.ac.uk
}

Received 23 May 2016; accepted 21 July 2016; published 25 July 2016

\begin{abstract}
Existing Metal Additive Manufacturing processes are fast approaching a matured stage in which a wide range of possibilities are available for the incorporation of the rapid fabrication technology to current industrial practices. In terms of design conventions, the limitless geometrical freedom allows complex structures including cellular internal grids and lattices to be formed without additional tooling. Repair parts and leveraging components can also be produced on demand when required especially for military assets where large volume of inventory is constantly maintained to ensure operational readiness. In this exemplary work, a feasibility study on using stainless steel material with integrated cellular design to manufacture a guide bracket found on a military vehicle via Selective Laser Melting process was conducted. The results showed appreciably better mechanical performance in using a stainless steel honeycomb as compared to the aluminum alloy used for the original component together with a faster production route through SLM.
\end{abstract}

\section{Keywords}

Selective Laser Melting, Design Optimization, Lightweight, Additive Manufacturing, Metallic Honeycomb

\section{Introduction}

Metal additive manufacturing (AM) techniques such as the Selective Laser Melting (SLM), Electron Beam Melting (EBM) and Direct Energy Deposition (DED) are known to create functional metallic components suitable for diverse industrial utilisations which possess high geometrical complexity and are difficult to produce using conventional means. The SLM process generates metallic models layer by layer through laser scanning and powder bed interaction according to a pre-set CAD file input. The design information is first sliced into single layers before sequential consolidations take place at controlled thicknesses by a descending built platform for repeated depositions to occur until the final part is completed. Various structural alloys including steel, titanium and nickel-based can be produced using the SLM process with comparable or often superior mechanical performance to traditional forming methods which can drive the additive technology adoption forward together with rising interests from major manufacturing sectors including aerospace, marine, military, biomedical and 
automotive industries.

Light-weighting possibilities are particularly favourable to aerospace and automotive sectors where bulk components can be converted into complex lattice structures to further enhance strength-to-weight properties [1]. It may also expand the basis of material selection in the specific area where a wider range of materials could be employed through redesigning of existing parts to achieve better strength with retained weight savings. The tooling industry takes advantage of the feasibility to increase cost efficiency through conformal cooling solutions which can promote more uniform heat dissipation for improved solidification and production rates [2]. Medical fields harness the freedom and flexibility in terms of implants and prostheses customisation as well as reducing the level of complexity during surgical operations [3]. Besides design optimisation opportunities, lead times can also be reduced with rapid design-to-part conversions without the need for additional fixtures or exhaustive machining operations which contribute to common delays in supply chain systems. Faulty components can also be repaired with additional ease through reverse mapping of damaged sites and direct replication of spare parts when required. Such supply chain revisions are especially important for military applications since large quantities of spare and obsolescence parts are typically stockpiled in order to support defence and peacekeeping activities which can incur high costs and inventory maintenance [4]. Maintenance tasks can also be performed more timely through on demand printing without the need of ferrying spares to remote areas which could save on transportation costs, reinforce security and enhance operational readiness. In addition, the relevance of additive technology to military activities was also recently tested on forward deployments with the introduction of Expeditionary Lab Mobile (ELM) (refer to Figure 1) in Afghanistan by the Rapid Equipping Force (REF) from the U.S. Army to print components for immediate usage which have largely decreased logistic footprint as well as the load carried by maintenance forces [5]. In view of such initiatives, the current holding inventory of military spare assets worth over USD 90 billion could be significantly reduced in the near future through increasing utilisation of additive manufacturing [6]. To reiterate on the beneficial effects of additive manufacturing adoption, the paper presents a case study on the feasibility of using an alternative material with proposed design modification to fabricate existing guide brackets found on a M3G military vehicle via the SLM process.

\section{Case Study}

\subsection{M3G Vehicle}

The M3G is an amphibious vehicle (refer to Figure 2(a)) produced in Germany to support military units in combat and peacekeeping missions. The military asset serves to provide structural transportation through bridging over waterways to effectively maintain mobility of troops and vehicles across water obstacles.

\subsection{Guide Brackets of M3G Vehicle}

The guide brackets (see Figure 2(b)) are mounted on the lower lateral faces of the M3G vehicle which primarily serve as supporting zones to accurately position bridge platforms during launching operations. Each bracket is

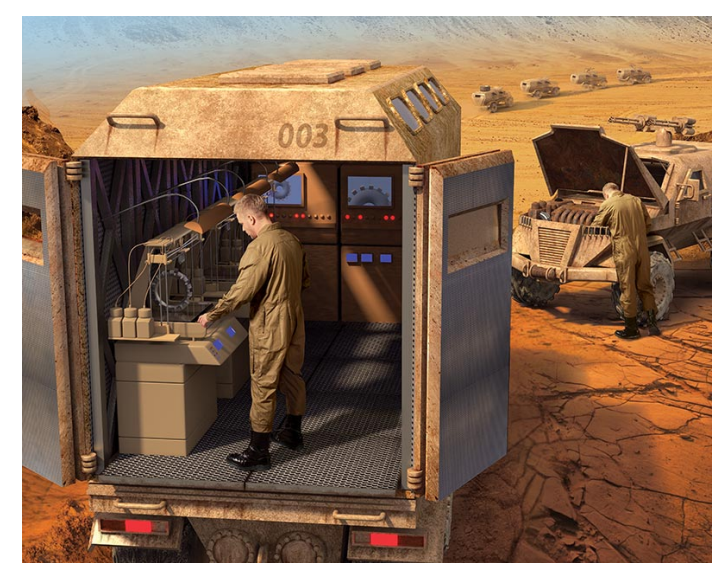

Figure 1. The concept of expeditionary lab mobile [7]. 


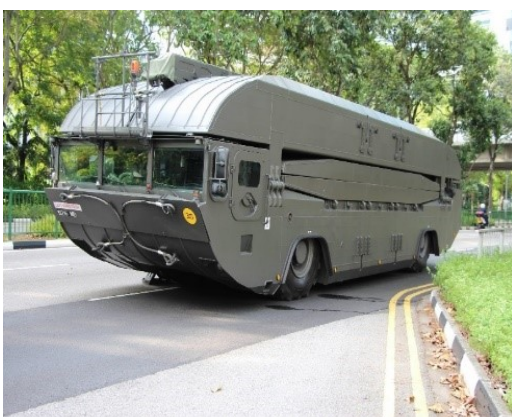

(a)

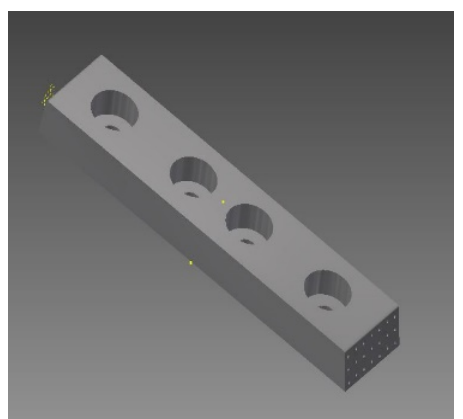

(b)

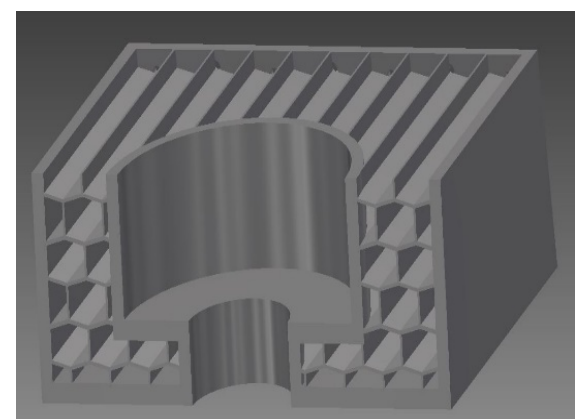

(c)

Figure 2. (a) M3G vehicle, (b) guide bracket model and (c) cross section of modified guide bracket.

manufactured from high strength $\mathrm{Al} 7020$ alloy commonly used for heavy loading applications such as construction cranes and bolted into place with four stainless steel screws respectively. The bracket is however subjected to unforeseen knocking or impact during vehicular movement in which it assumes the sacrificial part by absorbing most of the impact energy due to lower mechanical properties than steel and becomes more prone towards cracking upon foreign force application. Although the bracket is treated as a non-critical component and will not endanger general safety or result in catastrophic consequences, part failure will however deem the M3G platform as unserviceable which could hinder military operations. In addition, the replacement of damaged brackets requires long lead times as the part has to be procured from the overseas manufacturer. The aim of the current work is to investigate the use of SLM process as compared to conventional means in terms of the time required for design-to-part production as well as to realise the opportunities of widening material platforms and raising mechanical performance through structural design optimisation in producing identical components.

\subsection{Revised Design of Guide Brackets}

Cellular designed materials such as the metal honeycomb are commonly used in place of bulk components to achieve overall structural weight reduction or high impact resistance. The AM technology is capable of producing such internal grids with simple or very complex periodic patterns more efficiently as compared to conventional layup and bonding procedures required in sandwich panel construction for aerospace applications. In this study, a low cost stainless steel (17-4 PH) was suggested to fabricate the guide brackets as an alternative material in view of increasing the mechanical strength and avoiding preferential cracking. Since stainless steel is significantly denser than aluminium, a simple hexagonally shaped honeycomb design (see Figure 2(c)) was proposed for the internal structure construction of the guide brackets in order to match the original weight of the part and increase impact absorption. The metallic honeycomb design was developed based on geometrical parameters optimized for maximum energy absorption and minimum elastic buckling occurrence according to previous studies [8] [9].

\section{Experimental Procedure}

\subsection{Materials and Methods}

Pre-alloyed stainless steel powder (EOS Stainless Steel GP1) with material composition equivalent to the commercial 17-4 PH steel alloy and particle size range between $15 \mu \mathrm{m}-45 \mu \mathrm{m}$ was used to manufacture the test specimens with infilled honeycomb structures for Charpy impact, compression and micro hardness analysis. The stainless steel samples were produced from a Direct Metal Laser Sintering (DMLS) machine (EOSINT M280), equipped with an Ytterbium fibre laser and build capacity of $250 \mathrm{~mm} \times 250 \mathrm{~mm} \times 325 \mathrm{~mm}$, under optimised process parameters according to the machine manufacturer (EOS Systems) including a laser power of $195 \mathrm{~W}$. The mechanical tests were conducted on specimens of both the DMLS stainless steel and existing material (Al alloy 7020) for quantification purposes.

\subsection{Charpy Impact}

The stainless steel specimens were subjected to the Un-notched Charpy impact test according to ASTM E23 to 
determine the amount of energy absorption upon fracture under dynamic loading conditions. Impact testing was carried out using a KARL FRANK GMBH 53580 machine at room temperature of 23. Relief holes were included on a single longitudinal surface in the design of DMLS cellular samples to allow drainage of excess powder during fabrication.

\subsection{Compression}

The compression tests were performed according to ASTM E9 using a Instron 5982 universal testing machine with a maximum load of $80 \mathrm{kN}$ and strain rate of $1 \mathrm{~mm} / \mathrm{min}$. Similar to the impact test specimens, holes were purposefully added on the circular faces of cylindrical samples to prevent powder entrapment.

\subsection{Micro Hardness}

The micro hardness values of the test samples were measured using a Vickers hardness tester Minutolo HV 115 which consists of a square-based diamond pyramid indenter orientated at a point angle of $136^{\circ}$. The tests were carried out using an applied load of $3 \mathrm{kgf}$ (HV 3) with 10 seconds dwell time according to ASTM E384. A total of ten readings were taken along the longitudinal surface of the specimens and indent micrographs were captured under an optical microscope.

\section{Results and Discussion}

\subsection{Charpy Impact Test}

The geometrical configuration of a cellular unit is sensitive towards the direction of impact where structural responses vary according to different cell shapes used under a constant crushing motion. An in-plane (perpendicular to cell axes) or out-of-plane (parallel to cell axes) force application would also result in anisotropic behaviour with disparity in reaction forces which affects the overall stiffness, strength as well as impact energy absorption of a cellular part [8]. In this context, the impact location was targeted at the midpoint of the specimen surface with force exerted from an in-plane direction where the highest impact resistance could be observed when an optimized hexagonal honeycomb is employed [9]. While the cellular network is encapsulated inside the DMLS specimens, Figure 3(a) depicts the direction of swinging force acted on the internal structure. Based on the computed average results (summarised in Table 1), stainless steel honeycomb specimens yielded an improvement of $24.25 \%$ in the amount of energy absorbed as compared to cast $\mathrm{Al}$ alloy samples. Ductile failure was also observed at the fractured surface of cast Al specimens with evident tearing and twisting away from the point of impact (see Figure 3(b)). Conversely, the same impact energy was insufficient to cause failure in the stainless steel honeycomb samples with no visible cracks on the struck surface although severe plastic deformation and structural bending were clearly observed (refer to Figure 3(c)). The results suggest that DMLS stainless steel honeycomb structures possess stronger fracture resilience with higher apparent energy absorbance than a casted bulk $\mathrm{Al}$ alloy.

\subsection{Compression Test}

In the design of structural components, the permitted stress seldom extends beyond the yield point of the material

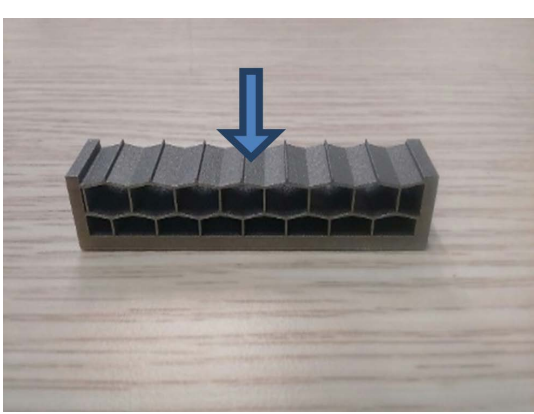

(a)

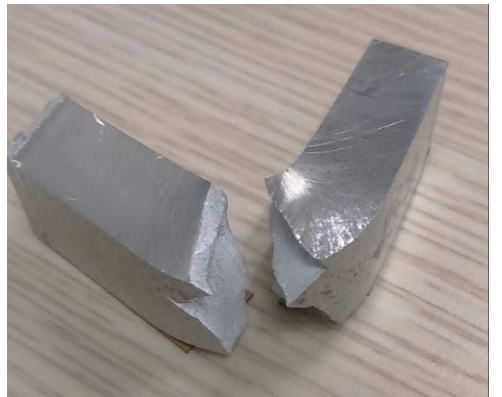

(b)

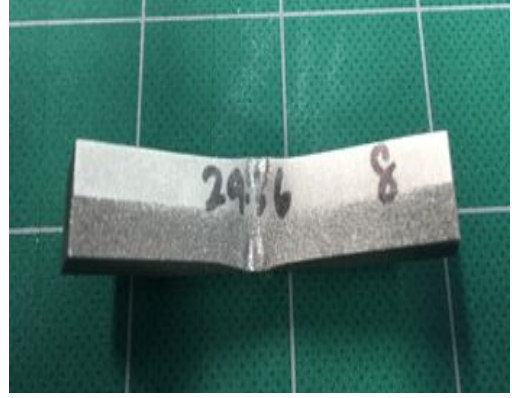

(c)

Figure 3. (a) Impact location, (b) Cast al alloy and (c) DMLS stainless steel honeycomb. 
and is capped below the elastic limit before the onset of plastic deformation to ensure structural integrity and safe part functionality. This study considers the compressive performance of the stainless steel honeycomb based on its yield strength in which only elastic buckling exists before the initiation of plastic buckling. The compression force was applied along the direction of the cell axes (out-of-plane) which tend to achieve maximum stiffness and strength [9]. The general deformation behaviour for all the DMLS stainless steel honeycomb samples can be represented by a stress-strain curve as shown in Figure 4. The compressive stress values were taken at the point of elastic-plastic collapse (yield limit) and the average yield strength of stainless steel honeycomb specimens was observed to be $>60 \%$ higher than cast $\mathrm{Al}$ alloy samples. The designed cellular structure was also found to be much stiffer than the original bulk material with a mean elastic modulus of $31.38 \mathrm{GPa}$ and $22.18 \mathrm{GPa}$ respectively.

\subsection{Micro Hardness Test}

Figure 5 shows the surface indentation micrographs of a cast Al alloy and DMLS stainless steel honeycomb sample respectively. The latter achieved significantly better hardness results with $194.5 \%$ increment over the $\mathrm{Al}$ alloy specimens, as expected of stainless steel material with higher compressive strength observed earlier.

\section{Conclusion}

The presented case study aimed to illustrate the benefits of utilising the design flexibility to widen the choice of materials for producing existing industrial components through AM technology adoption. It also demonstrated that the use of AM could shorten the waiting time for part fabrication through on demand printing as compared

Table 1. Comparison between cast al alloy and DMLS stainless steel honeycomb.

\begin{tabular}{ccccccc}
\hline Material & $\begin{array}{c}\text { Lead Time } \\
\text { (Est. No. of Weeks) }\end{array}$ & Weight (kg) & $\begin{array}{c}\text { Mean Compressive } \\
\text { Strength (MPa) }\end{array}$ & $\begin{array}{c}\text { Mean Young’s } \\
\text { Modulus (GPa) }\end{array}$ & $\begin{array}{c}\text { Mean Impact } \\
\text { Toughness (J) }\end{array}$ & $\begin{array}{c}\text { Mean Micro } \\
\text { Hardness (HV) }\end{array}$ \\
\hline Cast Al Alloy & $>12$ & 1.283 & 383.23 & 22.18 & 118.37 & 141.73 \\
$\begin{array}{c}\text { DMLS Stainless } \\
\text { Steel Honeycomb }\end{array}$ & 2 & 1.456 & 619.26 & 31.38 & 147.07 & 417.40 \\
Improvement (\%) & - & -13.48 & 61.59 & 41.48 & 24.25 & 194.5 \\
\hline
\end{tabular}

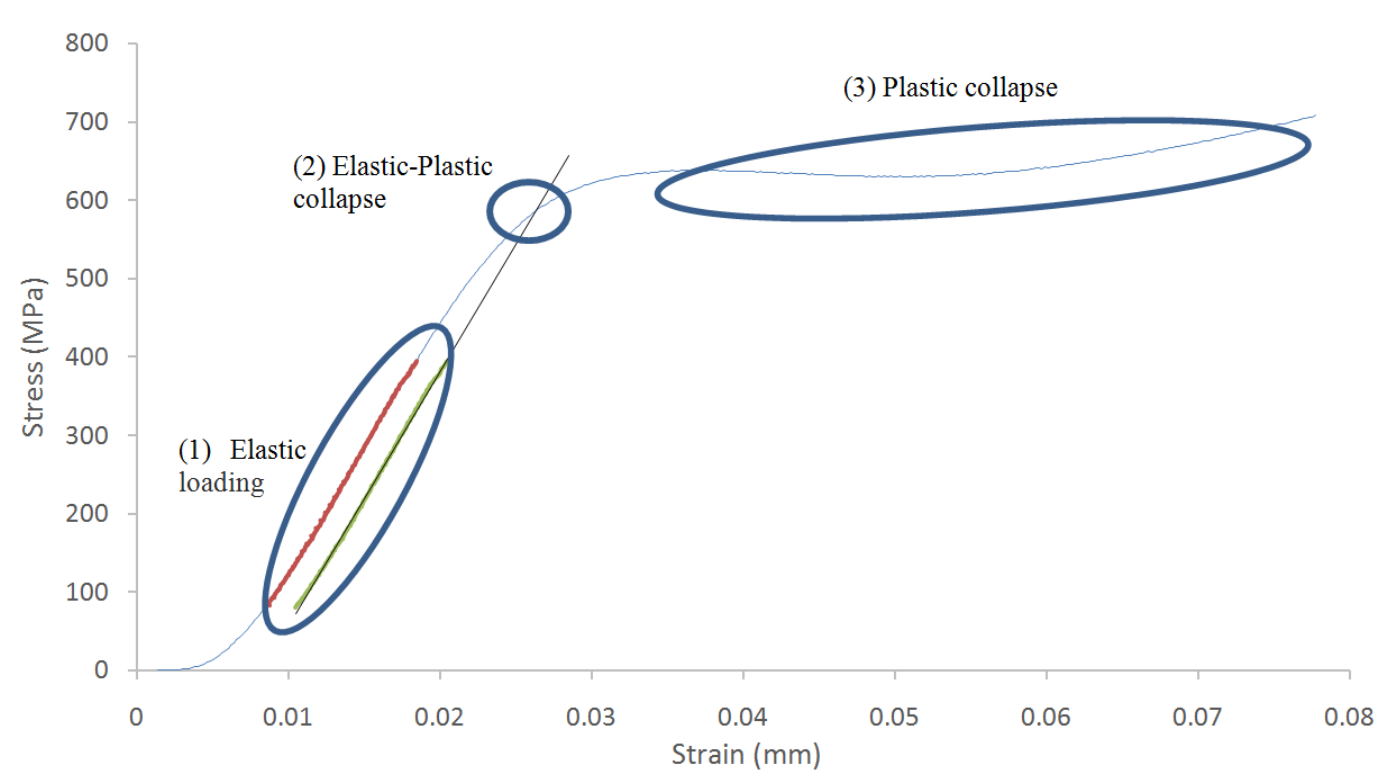

Figure 4. Deformation behavior of DMLS Stainless Steel Honeycomb. 

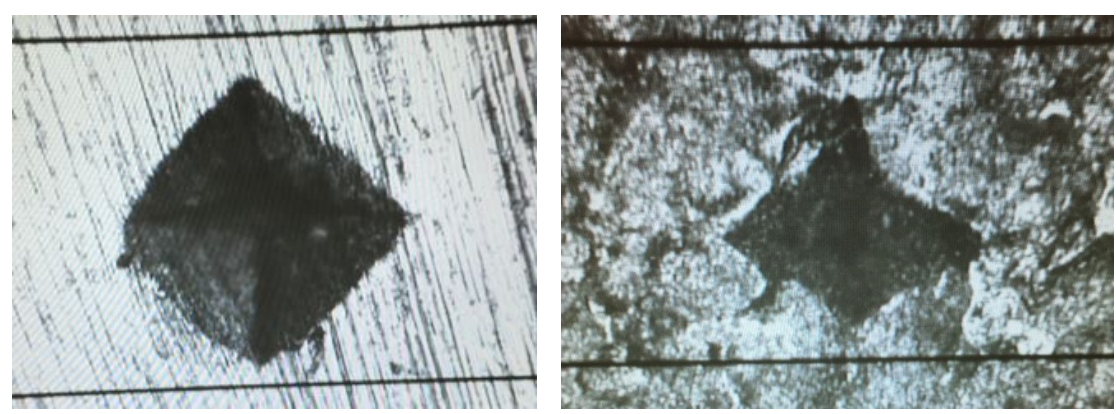

Figure 5. Indentation micrographs of Cast Al Alloy (left) and DMLS Stainless Steel Honeycomb (right).

to conventional methods which was particularly useful, but not limited, to military operations. Despite a small addition to component weight, the results clearly showed that a stainless steel honeycomb could be alternatively employed or perhaps replace the current bulk aluminium guide bracket with superior mechanical performance in conjunction with more desirable production time. However, further concerns over AM compatibility to the military sector may include the requirement for robust print-and-qualify part certifications, availability and processability of powder feedstock in harsh military environments as well as security issues involving the protection of sensitive design information.

\section{References}

[1] Rashed, M.G., Ashraf, M., Mines, R.A.W. and Hazell, P.J. (2016) Metallic Microlattice Materials: A Current State of the Art on Manufacturing, Mechanical Properties and Applications. Materials \& Design, 95, 518-533. http://dx.doi.org/10.1016/j.matdes.2016.01.146

[2] Campanelli, S.L., Contuzzi, N., Angelastro, A. and \& Ludovico, A.D. (2010) Chapter 13: Capabilities and Performances of the Selective Laser Melting Process. In: New Trends in Technologies: Devices, Computer, Communication and Industrial Systems.

[3] Huang, S.H., Liu, P., Mokasdar, A. and Hou, L. (2013) Additive Manufacturing and Its Societal Impact: A Literature Review. International Journal of Advanced Manufacturing Technology, 67, 1191-1203. http://dx.doi.org/10.1007/s00170-012-4558-5

[4] Hebert, R.J. (2016) Viewpoint: Metallurgical Aspects of Powder Bed Metal Additive Manufacturing. Journal of Materials Science, 51, 1165-1175. http://dx.doi.org/10.1007/s10853-015-9479-X

[5] Zhai, Y., Lados, D.A. and Lagoy, J.L. (2014) Additive Manufacturing: Making Imagination the Major Limitation. JOM, 66, 808-816. http://dx.doi.org/10.1007/s11837-014-0886-2

[6] Khajavi, S.H., Partanen, J. and Holmström, J. (2014) Additive Manufacturing in the Spare Parts Supply Chain. Computers in Industry, 65, 50-63. http://dx.doi.org/10.1016/j.compind.2013.07.008

[7] Louis, M.J., Seymour, T. and Joyce, J. (2014) 3D Opportunity for The Department of Defense. http://dupress.com/articles/additive-manufacturing-defense-3d-printing/

[8] Schultz, J., Griese, D., Ju, J., Shankar, P., Summers, J.D. and Thompson, L. (2012) Design of Honeycomb Mesostructures for Crushing Energy Absorption. Journal of Mechanical Design, 134, 071004. http://dx.doi.org/10.1115/1.4006739

[9] Wang, A.-J. and McDowell, D.L. (2004) In-Plane Stiffness and Yield Strength of Periodic Metal Honeycombs. Journal of Engineering Materials and Technology, 126, 137-156. http://dx.doi.org/10.1115/1.1646165 


\section{Submit or recommend next manuscript to SCIRP and we will provide best service for you:}

Accepting pre-submission inquiries through Email, Facebook, LinkedIn, Twitter, etc.

A wide selection of journals (inclusive of 9 subjects, more than 200 journals)

Providing 24-hour high-quality service

User-friendly online submission system

Fair and swift peer-review system

Efficient typesetting and proofreading procedure

Display of the result of downloads and visits, as well as the number of cited articles

Maximum dissemination of your research work

Submit your manuscript at: http://papersubmission.scirp.org/ 